Oliver Schülke

\title{
To breed or not to breed-food competition and other factors involved in female breeding decisions in the pair-living nocturnal fork-marked lemur (Phaner furcifer)
}

Published online: 13 November 2003

(C) Springer-Verlag 2003

\section{Behav Ecol Sociobiol (2003) 55:11-21}

Figure 1 shows only black and white symbols and lacks the grey color that codes for full-grown offspring of either sex. The figure below gives the complete information.

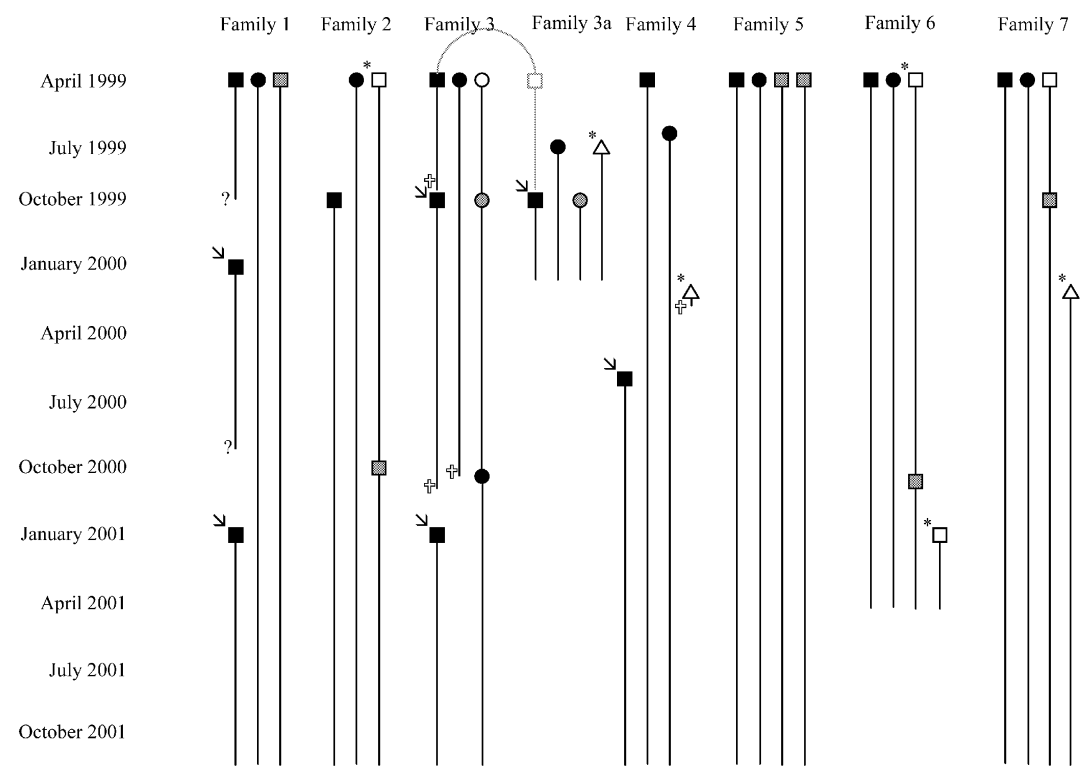

Fig. 1 Demography of all groups studied in Kirindy forest between 1999 and 2001. Individuals enter the chart when first identified unequivocally (black symbols adults; grey symbols full-grown offspring; white symbols not full-grown offspring; squares males; circles females; triangles sex unknown; * born the respective month or, in family $3 \mathrm{a}$, the same year; is found dead; ? fate

The online version of the original article can be found at http://dx.doi.org/10.1007/s00265-003-0676-2

O. Schülke $(\bullet)$

Department of Behaviour and Ecology,

German Primate Center,

Kellnerweg 4, 37077 Göttingen, Germany

e-mail: oschuel@dpz.gwdg.de

Tel.: +1-631-632-7643

Fax: +1-631-632-9165 unknown but no longer present in the territory; \immigrated from unknown family; lines that end without ? or \$ animals no longer monitored); male of family 3 ranged over the area of the female from family $3 \mathrm{a}$ for several months; subadult female of family 3 took over breeding position and grew to adult in her parents' territory

O. Schülke

Department of Animal Ecology and Tropical Biology, University of Würzburg,

Am Hubland, 97074 Würzburg, Germany

Present address:

Anthropology Department,

SUNY at Stony Brook,

S537 SBS Building, Stony Brook, NY 11794-4364, USA 